\title{
On the heredity trail
}

\section{Matthew Cobb assesses Siddhartha Mukherjee's history of human genetics.}

$\mathrm{I}$ 2011, Siddhartha Mukherjee won a Pulitzer prize for The Emperor of All Mal1 adies (Scribner, 2010), which intertwined science and his own experience as an oncologist. In The Gene, Mukherjee uses a personal approach to describe our understanding of heredity. Despite its subtitle ('An Intimate History'), the historical sections of The Gene, ranging from 1860 to the present, are not intended to show the convoluted route to current knowledge. They are primarily a tool for explaining the basics of medical genetics.

As a consequence, the complexities of the past are ironed out. Discovery is presented not as a messy reality full of dead ends, but as a linear thread leading inexorably to today. Conclusions of past experiments are presented in terms of modern understanding, rather than as a way to explore confused contemporaneous interpretations. This is a road often followed by scientists and clinicians who write history; it irritates historians, who know that the past was more complicated.

The first half of the book takes us up to the late 1960s and presents familiar, sometimes erroneous versions of past milestones. For example, nineteenth-century genetics pioneer Gregor Mendel appears as a lone genius. In fact, his work was part of a long-term interest in heredity on the part of Cyrill Napp, abbot of the monastery in Brno - now in the Czech Republic - where Mendel was a monk. This interest was prompted by the desire of local agriculturalists (including some at the monastery) to improve their animals and plants, and began nearly 20 years before Mendel planted his peas. Sometimes, the drama is downplayed. A brief footnote describes Vernon Ingram and Francis Crick's ground-breaking 1950s demonstration that the difference between normal and sickle-cell haemoglobin is caused by a single-base difference in the relevant gene. And one of the most exciting moments in genetics history - the 1960s discovery of how genes encode proteins - is passed over in a couple of lines.

The writing comes alive in the book's second half, covering the 1970s onwards, and introduced by Enlightenment poet Alexander Pope's line: "The proper study of mankind is man". Mukherjee, as a physician, rightly takes that declaration as his own. Here, the book does become intimate. Mukherjee's account of the development of biotechnology companies in the 1970s is enriched by personal recollections from Nobel-prizewinning biochemist Paul Berg, in whose laboratory

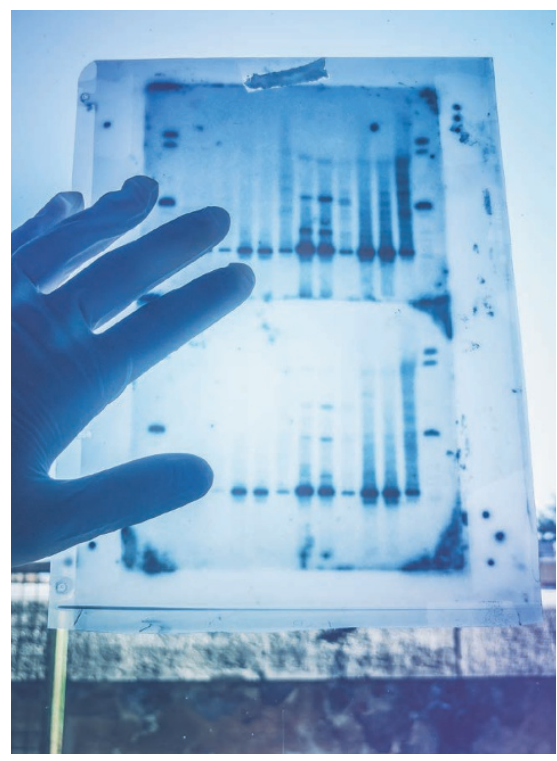

DNA analyses promise to change health care.

Mukherjee worked in the 1990s. The passages that describe patients with genetic diseases are full of the compassion that we would all wish from our doctors. At other points, Mukherjee brings in examples from his own family, in particular his uncle and cousin, who both had schizophrenia, to frame the narrative and form the starting point for his examination of the role of genetic factors in disease.

Mukherjee's account of how the genetic basis of Huntington's disease was discovered is particularly effective, covering the personal tragedies and the motivation of the scientists who made this breakthrough, including Nancy Wexler, whose mother died of the disease. There is an atmospheric description of Wexler's fieldwork region in Venezuela, where almost $10 \%$ of the population has Huntington's disease. An endnote candidly admits that these passages were inspired not by a visit to the region as I had imagined, but by a BBC Newsnight report about Wexler that can be seen on YouTube. Some writers are not so honest about pulling aside the curtain of creation.

However, one consequence of Mukherjee's medical focus is that some of the most stunning discoveries

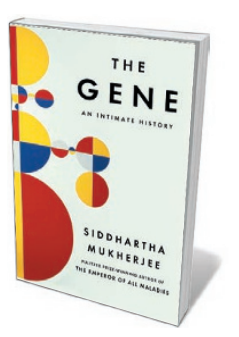

The Gene: An Intimate History SIDDHARTHA MUKHERJEE Scribner: 2016. from human genomics barely get a mention. Homo sapiens' interbreeding with Neanderthals is allotted two sentences, and our species' sexual encounters with the mysterious Denisovans are not mentioned. The genetic legacy of those interactions may help to explain aspects of epidemiology: there seem to be links between Neanderthal DNA and a number of immunological, dermatological and psychiatric conditions, such as depression and the skin lesions called actinic keratosis. Furthermore, because the book centres on medical genetics, anyone expecting an exploration of the state of genetics as a whole will be disappointed. Our Genes would have been a more appropriate title than The Gene.

A final section examines what Berg described to Mukherjee as "the future of the future" - the amazing possibilities for manipulating the human genome that are within our grasp. Mukherjee outlines the rise and fall of gene therapy in the 1990s, always with a clinician's compassion for the tragic stories behind the technology; and discusses the potential for gene modification with tools such as CRISPR-Cas9. This section concludes with some of what Mukherjee does best, combining stories of real patients with the ethical dilemmas raised by their conditions - in this case, what would happen if their disorders were the subject of prenatal or pre-implantation testing?

The Gene finishes with a manifesto for living in a post-genomic world. Mukherjee provides a 13-point 'opening salvo' that outlines our knowledge of human genetics and its implications. He concludes blandly: "we need new biological, cultural, and social precepts to determine which genetic interventions may be permitted or constrained, and the circumstances in which these interventions become safe or permissible". More-consistent grappling with the ethical, philosophical and historical debates that have swirled around these issues for decades might have led to a more detailed hint of what those precepts might be. This vagueness is frustrating: Mukherjee's visceral and thought-provoking descriptions of the horrors of early-twentieth-century US eugenics clearly show what he is capable of in this regard, both as a writer and as a thinker.

Matthew Cobb is professor of zoology at the University of Manchester, UK. His latest book is Life's Greatest Secret. e-mail:cobb@manchester.ac.uk 